\title{
Structure and pragmatics of a self-theory of memory
}

\author{
JEROME R. SEHULSTER \\ University of Connecticut, Stamford, Connecticut 06903
}

\begin{abstract}
Eight hundred ninety-three students completed statements from a questionnaire concerning their perceptions of their memory abilities. Twenty-nine memory domains and experiences, such as memory for smells or memory for names, were distributed across 60 statements in the questionnaire. A factor analysis yielded three meaningful factors: (1) a verbal memory factor, which included memory for names, trivia, and words; (2) a personal past memory factor, which included memory for childhood, dreams, painful experiences, and smells; and (3) an appointments factor, which included memory for appointments, personal articles, anniversaries, and so on. Factor scores from the first factor were used in two subsequent experiments: In one, factor scores correlated with performance on a trivia questionnaire; in the other, factor scores correlated with the amount of play money wagered in a twocontestant trivia quiz. Results of both studies suggested that attempts to validate the factors with behavioral measures would succeed. The framework of self-theory of memory was used in discussing the results and in suggesting directions for future inquiry.
\end{abstract}

The focus of this research is on the structure of a person's beliefs about his memory and the relationship between these beliefs and his behavior. Developmental aspects of memory beliefs have been explored by Flavell and his associates (Flavell \& Wellman, 1977) under the construct of "metamemory," and others (cf. Herrmann \& Neisser, 1979) have presented investigations of memory self-report and related behavior in adults. Although similar to these ventures, the research reported below differs from them in several important conceptual ways. First, a person's beliefs about his memory are seen as a subset of his beliefs about his self. That is, memory beliefs form part of the person's self-theory, and, as such, may be related to a number of other important dimensions of self grouped under the heading of cognitive style (Goldstein \& Blackman, 1978). Second, although an obvious question concerns the relationship between a person's memory beliefs and that person's actual memory behavior, the choice of the type of memory-related behavior is less obvious. For example, the amount of risk that a person is willing to take in a task that involves memory may prove to be a more sensitive measure of the influence of a person's memory beliefs than any measure of recall per se. Third, the

The author wishes to thank Leonard Katz and David Kenny for their assistance in the statistical thinking and Robert Sternberg and Harold Hawkins for their helpful comments on a previous draft of the manuscript. I also deeply appreciate the assistance of Elise Albert, Douglas Conway, and John Sarno in Experiment 3. My appreciation extends to those who gathered data from distant locations: in Delaware, John P. McLaughlin, George Cicala, and Barbara Fehr, and in Houston, Lynne Sehulster. Requests for reprints and copies of The Memory Scale with scoring instructions should be sent to Jerome $R$. Sehulster, University of Connecticut at Stamford, Scofieldtown Road, Stamford, Connecticut 06903. critical dimension of trust or certainty in one's memory may have profound consequences for his sense of personal identity and for his belief about the reality of his past (Sehulster, Note 1). His degree of trust in his memory may determine the person's willingness to take a stance in a memory-related discussion or his willingness to rely on his memory without mnemonic aids. The experiments reported below are the first steps in the exploration of the realm of a person's beliefs about his memory, his trust in his memory, and related behavior.

\section{A Self-Theory of Memory}

Statements such as "I have a good memory for faces" reflect a part of a theory of self. A theory of self is the subset of a person's cognitive theory of the world within and around him that concerns his self (Bateson, 1972; Kleinke, 1978; Shaver, 1975; Wegner \& Vallacher, 1977). Like a scientific theory, a self-theory contains a set of generalizations based on "evidence" accumulated from various sources. The most important source is direct experience (e.g., "I am aware that I cannot recall your name just now"). Specifically, by collecting experiences and categorizing them as instances of remembering and forgetting, a person gathers evidence on which to base generalizations about his memory ability. A second source of evidence is less immediate: The ways of categorizing, evaluating, labeling, or interpreting experiences may be based on the opinions or evaluations of other people. These opinions may be supplied directly (e.g., "Mother always said I had a poor memory for faces") or they may be inferred through a process of social comparison, either with a specific person or reference group (as suggested by Festinger, 1954) or with a "generalized other" (as suggested by Mead, 1934). Often, others will report 
evidence of their own to support their opinions or evaluations.

Although it is for the most part stable, a self-theory, once formed, is by no means a static structure. New evidence that accrues as the person experiences new situations or encounters new evaluations or opinions from others may force him to revise his theory of self. Festinger's theory of cognitive dissonance (Aronson, 1978) and Bem's (1978) self-perception hypothesis describe conditions under which revisions often occur. There are times, however, when a person will resist changing the self-theory, even when the theory of self constrains the person's behavior and narrows his cognitive field. This person may even distort or deny evidence that could force a revision. ${ }^{1}$ The possibility exists that a person's beliefs about his memory ability bear faint resemblance to his actual ability.

A first step in the description of the self-theory of memory is to inquire into the distinctions people perceive with regard to their memory ability. Anecdotal evidence suggests that people perceive themselves as having a good memory in distinct areas: How often have you heard the statement "I have a good memory for faces, but a poor memory for people's names" or the like? On the other hand, anecdotal evidence suggests that people perceive themselves as having a good memory or a poor memory in general. How often have you heard the statement "I have a good memory," without any reference to specifics? The first stage of this research explored the self-perception of memory ability with a questionnaire designed to elicit a person's opinions about his memory ability.

\section{EXPERIMENT 1}

One hears statements made about memory ability quite often in conversations. Twenty memory-related "domains" or content areas were chosen from those areas of life that typically appear in conversations about remembering and forgetting. A set of statements to be included in a questionnaire was constructed from the 20 memory domains or content areas. These 20 content areas are described below. The number of statements in each domain is given in parentheses following the name of the domain.

(1) Memory for songs (five)-The ability to recognize a song, a symphony, a musical group, a singer, a pianist, and so on, is an ability that is put to the test often. Two aspects of the domain included in the questionnaire were the recognition of melodies and the ability to remember the words to songs. Subjects were instructed verbally to think in terms of the songs or music they listened to with any frequency and then complete the statements.

(2) Memory for jokes (two)-The telling of a joke depends, of course, on the ability to remember how the joke goes. The inability to remember parts of the joke can determine a person's behavior at, say, a social gathering.
(3) Memory for trivia (two)-The trivia banter that often arises in group conversation demands a facility for rapid search and retrieval of names, titles, quotations, dates, and facts from memory. The subjects were instructed to think of discussions involving trivia about a favorite topic, be it rock and roll music, early television shows, films, baseball, Shakespearean plays, classical music, or whatever, and then to think of how they fared in these discussions.

(4) Memory for directions to a place (two)-The importance of the ability to remember how to get somewhere is illustrated by considering what life would be like without the ability. The statements captured two aspects of remembering how to get somewhere: first, the ability to remember the verbal directions to a new place, such as those given by a service station attendant, and second, the ability to remember the way to places visited infrequently.

(5) Memory for personal articles, such as pens, umbrellas, notebooks, car keys, hats, gloves, and so on (five)-The frequency with which people leave personal articles behind demanded the inclusion of these statements in the questionnaire.

(6) Memory for feelings, specifically for the feelings one had while reading a book or watching a film (two)The two statements were inspired by the comment "I don't remember what the story was all about, but I do remember being very upset at the end."

(7) Memory for names (four)-The four statements in this domain covered aspects of memory for names, including memory for the names of television, recording, stage, and film stars, the names of authors, and the names of characters from books and plays. It could be argued that the names of television, recording, and film stars are the very substance of the trivia domain (indeed, the two statements about television names yielded an average correlation of .380 with the trivia statements). However, it was decided to leave the trivia domain stated in the general form and group all of the statements concerning names in specific to a separate domain.

(8) Memory for faces and names (three)-Here, the three statements tapped the person's ability to connect the name with the face and the ability to remember a person's name after just meeting him.

(9) Memory for the plots of books and films (two)This domain was conceived as a companion to Domain 6. Here, the focus was on the experience of remembering what happened in the story but forgetting the experience of actually reading the book or watching the film.

(10) Memory for conversations (one)-The ability to remember what was said in conversation was certainly important for John Dean; it is important for all of us as well on a daily basis: Arguments, promises, reminiscenses, and the like depend on this ability.

(11) Memory for dreams (one)-Some people remember as many as two or three dreams per night, some in technicolor and stereophonic sound, whereas other 
people report little or no memory for dreams whatsoever.

(12) Memory for the distant past or childhood (three)-Three general statements were included in this domain of memory for the distant past. No age was specified in the statements: Each subject was instructed to define childhood with his or her own age boundaries.

(13) Memory for high school years (one)-This single statement was designed to give the subjects a comparison point with which to assess their memory for their past. It was assumed that most subjects would report that they remembered their high school experiences reasonably well.

(14) Memory for painful experiences (one)-A single, general statement tapped the domain of memory for painful experiences. No references were made to the time frame of the experiences, nor was the nature of the pain (i.e., psychological or physical) specified.

(15) Memory for smells (two)-Two aspects of memory for smells were touched here: first, the ability to identify smells and name them, and second, the ability to use smells as cues for remembrances of things past.

(16) Memory for words (one)-The single statement concerning memory for words was phrased in the negative: It concerned being at a loss for the correct word.

(17) Memory for appointments (two)-Two statements combined appointments, anniversaries, and birthdays in order to get at the domain of remembering dates (i.e., the ability to remember to do something in the future). The antidote for a failure to remember appointments is, of course, to carry an appointment book or tie the proverbial string around your finger.

(18) Memory for what one studies (one)-The most likely implication of this single statement is memory for course material that one studies. However, the statement was left in a general form so that any body of information memorized by the subject for later use would be covered.

(19) Memory for news events (three)-We often need to remember news happenings to support arguments, form opinions, infer trends, and draw conclusions about the world outside our immediate reach. No distinction was drawn in the statements concerning the source of the news event (i.e., newspaper, radio, television, or word of mouth).

(20) Memory for the lights and the locks (one)-This single statement referred to the general ability to remember to turn off the lights and lock up the car or the house.

The 20 memory domains were not intended to be exhaustive. Rather, an attempt was made to draw a representative sample of those areas of life in which people use memory. People are often heard making statements about memory in these areas; they speak as if they are aware of differences in memory ability.

Nine memory experiences were included with the 20 memory domains in order to explore the relation- ships among the memory domains, which refer to content of memory, and typical memory experiences, such as going blank on a test or having your memories continually fail to correspond with those of your friends, and so on. These memory experiences may be totally independent of the contents of memory. However, they may occur more frequently with some people than with others, and it may follow that the experiences are related to certain memory contents. For exanıple, the person who perceives himself as likely to go blank on a test may perceive himself as having a poor memory for what he studies. Does trust in one's memory tend to coincide with a good memory for, say, appointments and personal articles? Questions such as these could be answered by including various memory experiences along with the content domains as additional variables in the analysis. The nine memory experiences are as follows:

(1) False certainty, or the feeling of being absolutely sure that an event happened as remembered and finding, subsequently, that it did not happen as remembered (four)-The experience can be quite unsettling and, if frequent, could undermine one's faith in one's memory and could at least force a revision of one's selftheory of memory. The experience could as likely be the result of an indiscriminant sense of certainty as the result of a faulty memory.

(2) Trust in one's memory (one)-Trust was dealt with by a single statement: "I trust my memory more than I trust the memory of ___.." Implied was the determinant of behavior in a situation in which two people disagree over the course of some event in the past. Whose memory is trusted as the final word? Trust in one's memory implies that the evidence served up by the memory is valid.

(3) The experience of drawing a complete blank (one)-A single statement captured this experience. It is similar to the experience of being at a loss for the correct word (the correlation between the two was .230), yet, the experience of drawing a blank can be more broad: It can happen with regard to any content of memory.

(4) Memory correspondence (two)-The two statements asked the subject to think of how often he found his memories for a situation or an event to correspond to the memories that others have for that situation. Put in the negative form, the statements would express the retort "That is not how I remember the evening in question."

(5) Memory correspondence for high school events (one)-This single statement was designed to give subjects a comparison point with which to assess the general memory correspondence alluded to above. It was assumed that most subjects would report that their memories of high school days corresponded to those of others.

(6) Locating objects through memory search (two)The two statements tried to get at the experience of locating an object, say, a squash racket, merely by a 
mental search of the possible locations. The statements in the questionnaire added the element of speed to the experience: The subject had to be able to locate the objects not only successfully but also faster than others in order to rate himself highly.

(7) Failure to locate objects through memory (two)Here, behaviors were specified in the two statements that make up this experience: If memory fails to locate the object, does the person stop thinking and start a frantic perceptual/behavioral search?

(8) Failure to locate objects through memory (one)This statement captured the situation in which one person accuses another of removing or stealing the object when the object is not in the location suggested by memory.

(9) Social comparison of memory ability (two)-The two statements asked the subject to make a direct assessment of how his memory compared with that of others. Of interest was which memory content areas or domains are associated with a person who perceives himself as having a better memory than others?

The 20 memory domains, which represented various contents of memory, and the nine memory experiences, which represented various mnemonic situations or experiences, constituted the 29 variables in the factor analysis.

\section{Method}

Subjects. A total of 893 subjects completed The Memory Scale over a 2 -year period from fall 1978 to spring 1980 . Subjects ranged in age from 17 to 54 years and ranged in education from college freshmen to faculty members. The majority of subjects were college students recruited in college psychology classes. The breakdown of subjects by location and dates was as follows: 410 subjects from the University of Connecticut at Stamford, $1978-1980 ; 452$ subjects from the University of Delaware at Newark, 1979; and 31 subjects from the College of Medicine of Baylor University at Houston, 1979. Smaller subsets from the 893 subjects were used in various aspects of the experiments reported here. All 893 subjects were used in the factor analysis reported below.

Materials. A three-page, 60 statement questionnaire, titled "The Memory Scale," was constructed. Each statement expressed one of the memory domains or memory experiences and required that the subject complete it with one of five choices from a scale given at the top of each page of the questionnaire. The 20 statements on the first page were completed by choices from an evaluative scale on which " 1 " equaled "very poorly" and " 5 " equaled "extremely well." An example is "I remember conversations that I had with other people ." The next 20 statements, on the second page, were completed by choices from a frequency scale on which " 1 " equaled "very often" and " 5 " equaled "rarely." An example is "I forget anniversaries, appointments, birthdays, etc. ". The final 20 statements were completed by choices from a social comparison scale on which " 1 " equaled "all or most people" and " 5 " equaled "very few people." An example is. "I trust my memory more than I trust the memory of

Several statements were phrased in the "I forget" form rather than in the "I remember" form; these statements required a reversal of the scale prior to analysis. Furthermore, the 29 memory domains and experiences were not equally represented in the 60 statements, nor were they equally spread across the three scales. Grouping of scores according to memory domain or experience and the averaging of scores were required prior to analysis.

Procedure. The Memory Scale was administered to subjects in groups, although in some cases subjects were tested individually. Each subject received a copy of the scale and was instructed to make a separate answer sheet. Subjects at the University of Delaware were instructed to fill in appropriate slots of an op-scan sheet. The instructions at the top of The Memory Scale were as follows.

"The purpose of these statements is to sample your attitudes toward your own memory ability. I want you to think about each statement and then place the number which corresponds to your opinion or attitude in the appropriate box on the answer sheet. Please be as objective as possible.

"Memory ability is not related to general intelligence level; your scores will not reflect on your ability as a student. There are no right or wrong answers to this set of statements; you will not be graded in any way on your performance in this task."

Verbal instructions were provided to clarify any ambiguities, especially in the cases of songs and trivia. Any questions were answered immediately. The average time required to complete The Memory Scale was about $25 \mathrm{~min}$. All answer sheets and copies of the questionnaire were collected at the end of the testing session.

\section{Results}

Raw scores were transcribed to computer cards. Score values were reversed for those statements that were phrased in the "I forget" form, so that a score value of " 5 " represented the perception of an excellent memory in all statements. The scores for all statements within a memory domain or memory experience were summed and divided by the number of statements within the domain, thus yielding a mean rating per memory domain. This was done to equate the weight of each domain and experience and to avoid the creation of spurious factors through overlapping items (Nunnally, 1978).

An exploratory factor analysis was performed on these data using the factor analysis program of Version 6 of the Statistical Package for the Social Sciences (SPSS) (Nie, Hull, Jenkins, Steinbrenner, \& Bent, 1975). Initial factors were extracted by a principal-components method in which the elements of the main diagonal of the correlation matrix are replaced by estimates of the communalities for the variables (PA2). Earlier analyses, done in $1979,^{2}$ had the minimum eigen value set at 1.5; these solutions yielded three factors. As these were conceptually clear and meaningful, the present analysis constrained the number of factors extracted to three.

The first factor accounted for $14.2 \%$, the second factor accounted for $7.7 \%$, and the third factor accounted for $5.8 \%$ of the total variance.

An oblique (OBLIMIN) rotation was used with these three factors. ${ }^{3}$ The oblique rotation method was chosen so as to allow any relationships among the factors to emerge. The resulting factor structure is reported in Table 1. The average correlation among the defining variables (loading $>.400$ ) within Factor 1 was .223; it was .261 within Factor 2 and .278 within Factor 3. 
Table 1

Factor Analysis: Factor Structure Following Oblique Rotation of Three Factors

\begin{tabular}{|c|c|c|c|c|}
\hline \multirow[b]{2}{*}{ Variables } & \multicolumn{3}{|c|}{ Loadings on the Factors } & \multirow{2}{*}{$\begin{array}{c}\text { Average Cor- } \\
\text { relation* }\end{array}$} \\
\hline & 1 & 2 & 3 & \\
\hline \multicolumn{5}{|c|}{ Memory Domains } \\
\hline 1 Songs & .280 & .190 & .107 & .428 \\
\hline 2 Jokes & .294 & .192 & .086 & .582 \\
\hline 3 Trivia & .446 & .311 & .071 & .680 \\
\hline 4 Directions & .246 & .129 & .195 & .561 \\
\hline 5 Personal Articles & .186 & -.043 & .759 & .335 \\
\hline 6 Feelings & .164 & .584 & .027 & .474 \\
\hline 7 Names & .424 & .347 & .106 & .330 \\
\hline 8 Faces/Names & .167 & .262 & .261 & .465 \\
\hline 9 Plots & .406 & .374 & .017 & .504 \\
\hline 10 Conversations & .293 & .425 & .231 & \\
\hline 11 Dreams & .077 & .356 & .032 & \\
\hline 12 Childhood & .215 & .510 & .111 & .548 \\
\hline 13 High School Events & .148 & .393 & .045 & \\
\hline 14 Painful Experiences & -.033 & .514 & -.066 & \\
\hline 15 Smells & .120 & .318 & .073 & .482 \\
\hline 16 Words & .422 & .020 & .195 & \\
\hline 17 Appointments & .153 & .156 & .453 & .291 \\
\hline 18 Studied Material & .489 & -.011 & .185 & \\
\hline 19 News & .518 & .288 & .245 & .212 \\
\hline \multirow[t]{2}{*}{20 Lights/Locks } & .121 & -.003 & .394 & \\
\hline & \multicolumn{3}{|c|}{ Memory Experiences } & \\
\hline 1 False Certainty & .540 & .170 & .260 & .261 \\
\hline 2 Trust & .373 & .046 & .268 & \\
\hline 3 Blank & .433 & -.122 & .154 & \\
\hline 4 Memory Correspondence & .107 & -.072 & .105 & .211 \\
\hline 5 Memory Correspondence High School & .206 & .181 & .125 & \\
\hline 6 Locate: Mental Search & .223 & .027 & .539 & .393 \\
\hline 7 Locate: Behavior Search & -.038 & -.004 & -.061 & .281 \\
\hline 8 Locate: Accuse & -.111 & -.047 & -.118 & \\
\hline 9 Social Comparison & .578 & .181 & .380 & .515 \\
\hline
\end{tabular}

*Within domain

The correlation between Factor 1 and Factor 2 was .242 , that between Factors 1 and 3 was .370 , and that between Factors 2 and 3 was .068.

Factor scores were calculated for each subject from the three factors and the subjects' raw scores. Each factor score can be conceived of as a representation of the subject's perception of himself on the memory abilities tapped by a factor.

Factor scores from the sample of 80 subjects from the spring 1980 semester at the University of Connecticut at Stamford had the following characteristics: The mean factor score for Factor 1 was - $.0306(\mathrm{SD}=.8137)$, the mean factor score for Factor 2 was -.2786 (SD = .8669), and the mean factor score for Factor 3 was .0949 $(\mathrm{SD}=.8425)$. Of the 80 subjects in this sample, $40 \%$ (32) were male and $60 \%(48)$ were female. When the three sets of factor scores were grouped according to sex, an interesting pattern emerged: Although the distributions of factor scores for males and females were quite similar for Factors 2 and 3, the distributions were distinctly different for males and females with respect to Factor 1. Males had a higher mean factor score (.3347) than the females $(-.2741)$ and were more frequently represented in the high-positive end of this sample distribution than would be expected. To make the point (and for use in subsequent studies), the subjects were divided into three groups according to the value of their factor scores on Factor 1. A subject was grouped into the "high" group if the factor score was above 1 standard deviation of the sample distribution (i.e., above a factor score of +.7831); a subject was grouped into the "low" group if the score was below 1 standard deviation; and all subjects whose scores were between +1 and -1 standard deviation were classified as "middle" subjects. A 2 by 3 table (sex by factor score classification) was constructed and each subject was assigned to a cell in the table. The chi square for the distribution of subjects according to sex and factor score for Factor 1 was 10.219 (df $=2$, $\mathrm{p}<.01)$. When a similar analysis was done for the other two sets of factor scores, the chi squares were both less than 1.00, indicating that males and females were similar with respect to Factors 2 and 3. The mean factor scores for males and females were similar in value on these two factors.

Thirty-three subjects who had completed The Memory Scale in September 1979 returned to complete the scale again in February 1980. They were instructed to fill out 
the questionnaire without any deliberate attempt to remember how they had completed the statements in September. All other instructions and procedures were the same as those reported in the previous section. A test-retest correlation was calculated for each subject by correlating his responses to the 60 statements on the first test with his responses to the 60 statements on the retest. The mean test-retest correlation for the $33 \mathrm{sub}$ jects was $.637(S D=.116)$. The highest correlation was .834 and the lowest was .409 . The mean test-retest correlation for the males was $.605(\mathrm{SD}=.136 ; n=12)$; the mean correlation for the females was $.655(\mathrm{SD}=$ $.103 ; n=21$ ). Scores from 70 subjects were paired randomly to yield 35 "chance" correlations for comparison with the test-retest sample: The mean "chance" correlation was $.220(\mathrm{SD}=.204)$; here, the highest observed was .595 and the lowest was -.180 .

The right column in Table 1 presents the mean of the correlations in the upper off-diagonal triangle of the correlation matrix formed by the individual statements of a domain. A mean correlation is presented for each domain having two or more statements. The correlations used in this separate analysis were taken from the 60 by 60 correlation matrix of the intercorrelations among the 60 statements in The Memory Scale. All 893 subjects were represented in the matrix.

\section{Discussion}

The results suggest that subjects draw subtle distinctions in their perceptions of their memory abilities. The factor analysis solution places these perceptions into three distinct clusters: For instance, the person who perceives that he has an excellent memory for his childhood is also likely to perceive that he has an excellent memory for painful experiences, and so on. The three clusters should not be construed as three different selftheories of memory ability; rather, they can be understood to reflect three general areas within a person's self-theory of memory ability. A set of three factor scores, one for each factor, represents a subject's position with regard to these three general areas of beliefs. An examination of the set of factor scores for a subject can reveal what a subject believes, in general, about his memory abilities.

The factor analysis yielded three content-defined clusters of beliefs about memory ability; it is to these that we now turn our attention. The discussion that follows is intended as an exploration of possible organizing schemes for understanding these clusters of beliefs. It is intended to be speculative, suggestive of paths of future research, and is in no way a final statement on the nature of the three factors. Subsequent research will no doubt eliminate or refine several of the possibilities suggested here.

Factor 1 suggests a verbal coding or representation of experience. It contains memory for the spoken word, memory for the studied word, memory for the name, memory for the trivia fact, memory for the news event, and so on. The concept of studying or memorizing is implied by Factor 1: Whereas one would not typically consider "memorizing" events from one's past, memorizing words or memorizing facts for school or for discussion is a common endeavor. Of course, one major purpose of schooling is to instruct children in a more verbal way of representing the world, and it is not surprising that when children are taught mnemonic skills they are trained with strings of words, letters, numbers, or facts. Memory for jokes and memory for the plots of books and films complete the picture, although the loadings are low.

Factor 1 seems to represent the dimension on which people assess the comparative value of their memory ability. If the retention of the verbal and the abstract lie at the foundation of our education system, and if success in this competitive context is dependent on a well oiled and often tested memory for these items, then it is reasonable to expect the verbal content areas to be at the base of social comparisons. The student probably has a good idea of how well his memory ability compares with that of his peers by the time he has reached college. The generalizability of this observation may be somewhat weakened, however, by the fact that the vast majority of subjects in this experiment were college students.

Trust in one's memory is also associated with the content areas of Factor 1, as are the experience of being certain of a memory, and subsequently discovering that one is mistaken, and the experience of going blank on a test. It is assumed that the latter two experiences are infrequent for the person who trusts his memory or thinks that his memory is better than that of others. As the content areas of Factor 1 are subject to frequent testing, it is not surprising to find the experience of trust clustered in this factor. Factor 1, then, can be considered a verbal memory factor and may be understood as the basis for social comparisons. It represents an order of memory different from the personal, experiential memory represented in Factor 2.

The two aspects of Factor 2 yield an interesting composite. The first aspect, memory of the past in general or memory for one's distant childhood, suggests that this factor concerns the person's perception of his memory for his personal history: his memory for events, both internal and external, which he experienced directly. The second aspect, memory for feelings one had at the cinema or while reading and memory for painful experiences, suggests that the encoding of personal experiences can have autonomic characteristics. The memories for these experiences may be both very richly encoded and intense. The memory domains with somewhat lower loadings are consistent with this interpretation: Memory for high school events, for faces and names of acquaintances, for conversations, and for dreams are memories for events that were directly experienced and personal; the ability to identify smells suggests another autonomic mode of encoding experiences. Factor 2 may be con- 
sidered the personal past factor; it is the memory for the personal past that is most often studied by philosophers (cf. James, 1950; Malcolm, 1977; Russell, 1921) and is recently the subject of some interesting psychological investigation (Linton, 1979).

Factor 3 is clearly represented by the ability to keep track of personal articles, such as pens, umbrellas, notebooks, car keys, and so on. The ability to locate objects by memory alone is also a skill represented by this factor, as are the abilities to remember and keep appointments, to remember birthdays and anniversaries, and to remember to turn off lights and lock up. The word used to describe the negative side of this factor would be absentminded or forgetful. The memory highlighted by Factor 3 has two aspects: First, it is a memory for the future, or, more exactly, a memory for an agreement or a desire to do something in the future. The agreement was made in the past, and, hence, it must be remembered in order to be met. This aspect extends beyond appointments to personal articles, in that taking your umbrella to the office constitutes a tacit agreement to remember to return home with it. The second aspect concerns the constant updating and erasing that must occur in memory in order to keep track of personal articles and dates. It does one little good today to remember where one parked yesterday or to remember that one wore a hat in the restaurant yesterday (unless, of course, this information is important for other reasons). We engage in directed forgetting and memory revisions on a daily basis in order to cope with constantly changing conditions. One might argue that the memory for where we parked yesterday is never completely purged, for it seems available for an extended period of time and can be retrieved if needed. Rather, it seems as if the memory for yesterday's parking spot is reconstructed as a completed action that is part of the personal past, which, although not relevant to locating the car today, may be relevant to some other query. Confusions may arise if the temporal organization surrounding these memories is not clearly structured.

\section{Implications for a Self-Theory of Memory}

It should be kept quite clear that we are dealing with statements from a subject's self-theory: The three factors represent clusters of self-perceptions. In and of themselves, the factors provide us with a glimpse of the major components of a self-theory of memory. But beyond these findings, an investigation of equal importance to that of the structure of a self-theory of memory concerns the pragmatics of the self-theory: the relationship of the self-theory to other aspects of the person's cognitive and behavioral world. As the factor scores suggest, individuals differ in their perceptions of their memory abilities: Are there other areas of the subject's world that parallel these perceived differences in memory ability?

An obvious starting point is the area of memory ability itself: How do the subject's perceptions of his memory ability relate to his actual memory ability? A substantial quantity of research, under the general heading of metamemory research, has yielded mixed results. Herrmann (Note 2) has reviewed several such research efforts. Part of the difficulty of establishing the relationship between perception of ability and the actual ability is that the perception of ability may depend as much on characteristics of the comparison group or on the person's overall concept of himself as it does on the ability itself. The relationship between self-perception of memory ability and actual ability is further clouded by a paradoxical situation for questionnaires of this type: The person with a poor memory may not be able to recall evidence from his past with any degree of accuracy, thereby rendering his selfreports, which are supposedly based on valid evidence, open to question. Herrmann (Note 3) has presented several detailed considerations of the influences at hand when a subject fills out a memory questionnaire.

Despite these difficulties, it may be possible to support the three-factor structure of a self-theory of memory by showing that memory abilities cluster in similar patterns. An approach similar to that reported in Underwood, Boruch, and Malmi (1978), but with a much wider sampling of memory domains and tasks, may yield an experimental confirmation of the three clusters of perceptions within a self-theory of memory. The success of the research effort will be threatened, however, by the very real difficulties in setting up memory tasks to tap the abilities clustered in Factor 2 .

The highest loadings on Factor 2 concerned memory for emotional experiences and personal past experiences. It would be difficult, if not impossible, to obtain any independent verification of a subject's remembrances for these experiences, and, even if an independent account were obtained, the scoring of accuracy of recall would be hopelessly subjective. But there may be ways to circumvent these difficulties: For instance, a person who claims to have a vivid memory for emotional experiences may also have a larger vocabulary with which to express these memories. An adjective-generation task may reflect individual differences: The person who perceives himself to have an excellent memory for emotional experiences may generate more emotionally loaded adjectives or may be faster in producing an emotionally loaded adjective. Or perhaps this person will score higher on several measures in a memory task that uses an emotionally charged conversation as the learning material. Such a study is presently being completed. It may even be necessary to place the subject in a social context in order to observe memory-related differences: Perhaps this person will generate longer, more detailed remembrances of the past or will be more willing to engage in a conversation that involves relating memories of the past. This willingness could be measured 
by the length of time or the frequency with which the person speaks. In these ways, we may obtain some validation of Factor 2.

Further speculation leads us to consider the possibility of the existence of memory systems that correspond to the factors listed above. The temptation is increased by some affinities between the memory systems implied by the factors and other well established systems in cognitive theory. For instance, the memory system suggested by Factor 2 remains more perceptual and experiential. It is possible that the hemisphere chiefly responsible for language mediates the coding for the memory system implied by Factor 1 and the other hemisphere mediates the coding for the more nonverbal memory system implied by Factor 2 . If this is so, scores representing hemispheric dominance should be related to the factor scores derived from the factors reported here.

Or, since the memory system implied by Factor 2 concerns one's personal past, it can be considered a memory for episodes structured in a time-order framework. It suggests an episodic memory as opposed to a more semantic or verbal memory, suggested by Factor 1. The formulation is a bit at odds with the episodicsemantic memory distinction proposed by Tulving (1972): His construct of episodic memory was created to deal with data that suggest that time-structured episodes are part of the special encoding used by subjects to store lists of words. The factors here suggest that memory for words is distinct from the memory for personal episodes. While it is still too early to make any definitive statement concerning the existence of separate memory systems as represented by the factors reported above, it may be profitable to generate hypotheses from existing theories of memory systems and investigate the relationship between a subject's beliefs about his memory and his memory performance.

It is conceivable, however, that the three factors of beliefs about memory ability reflect more an expression of interests than an expression of memory abilities per se: A person who is interested in baseball will naturally read about, talk about, and think about baseball more than a person who is interested in Italian opera. As the person's interest develops, he will notice many aspects of baseball that others may miss, he will understand events in a different, richer way, and he will be able to draw on a web of associations from the past as aids to the recall of any fact. It is not surprising that this person would remember facts about baseball better than the opera fan; it is not surprising that this person can learn new facts about baseball faster than the latter; nor is it surprising that the former would report having a good memory for trivia about baseball. It still does not follow, however, that the former has a different memory system or a different type of memory ability, in the sense of process or capacity, from the latter. This explanation suggests that statements concerning inter- ests, without mention of memory ability, should yield patterns similar to those suggested by the clusters of the self-perceptions of memory ability. This avenue is explored in a forthcoming study (Sehulster, Note 4). Of course, it is always possible to argue that the reason the person developed the interest in the first place was because he found that he had a superior memory ability for the material of interest. The point will remain moot.

\section{EXPERIMENT 2}

One step in establishing the validity of the factors is to show that factor scores are related to actual memory ability. For this, the abilities represented by Factor 1 are more easily adapted to an experimental design than are those represented by Factor 2. Experiment 2 was designed to show that factor scores from Factor 1 can predict differences in memory ability for verbal material while factor scores from the other two factors remain unrelated to the ability. The target ability, memory for television and cinema trivia, was one of the domains that had a high loading on Factor 1.

\section{Method}

Subjects. Sixty-eight students from the basic psychology classes participated in this study. The study was conducted at the University of Connecticut at Stamford during the spring semester of 1979.

Materials. A 46-question trivia questionnaire was constructed. Upperclass students aided in the construction of the questionnaire by suggesting popular television shows and recent films that were of ten seen by students of 18 or 19 years of age. There were nine categories of trivia used in this questionnaire.

(1) The Superman movie-Seven questions asked for the names of the actors and actresses who starred in this recent film.

(2) Saturday Night Live-Seven spaces were left for a listing of the names of the seven featured stars (as of spring 1979) of this favorite late-night comedy show.

(3) Star Trek-Names of characters and actors were required as answers to the six questions about this television classic that is continually rerun on local television.

(4) The Wizard of $\mathrm{Oz}-\mathrm{Six}$ questions required the names of the stars of the Judy Garland classic (shown annually on local television).

(5) Best Picure of the Year-The titles of the Academy Award winners for 1974-1978 were required as answers to the five questions.

(6) The Man from U.N.C.L.E.-The names of the three male stars of this past popular television show were required for the three spaces.

(7) Get Smart-The names of the three stars of this popular television show were required for the three spaces.

(8) The Twilight Zone-The name of the host of the famous show was required as an answer to this single question.

(9) The Honeymooners-The names of the four characters and the names of the four stars of the original television show were required for the eight spaces. This show is constantly rerun in this area.

The answers to the 46 questions were verified by upperclass trivia experts.

Procedure. The instructions were printed on the top of the first page of the questionnaire. The instructions are as follows: "This quiz is designed to test your knowledge of TV and movie trivia. In some cases you may not have seen the TV show or the movie in question, but try your best to answer each question." 
Subjects were given as much time as needed to complete the questionnaire. Papers were collected and the subjects were dismissed.

\section{Results}

Answers were counted correct if they were complete and spelled within a phonetic approximation of the correct answer. This allowance was introduced to cover the case in which the subject had heard the name of the character in conversation but had never actually seen the credits of the film or television show. Subjects were given scores for the following aspects of trivia recall. (1) The number of categories of trivia attempted (of the nine possible categories). (2) The number of categories in which a correct answer appeared. (3) The number of categories completely correct (all questions within the category correct). (4) Total number of correct answers (of 46 questions). (5) Total number of incorrect answers (omissions were not included in the number of incorrect answers). (6) Total number of questions attempted (sum of the correct and incorrect answers).

Factor scores from the three factors were calculated by the factor analysis subprogram of SPSS as part of the solution reported in Experiment 1.

The correlation matrix for the factor scores from the three factors and the six measures of trivia recall is presented in Table 2. A comparison of the correlations for factor scores from Factor 1 and Factor 2 shows that Factor 1 is clearly related to successful performance of the trivia task, whereas Factor 2 is not relevant to any measure of trivia recall. Factor scores from Factor 3 show a strong relationship to the number of questions answered incorrectly and to the number of questions attempted (which is a composite of number correct and number incorrect). Neither the sex nor the name of the subject was recorded on the questionnaire, thus making it impossible to report any male-female differences.

\section{Discussion}

The results clearly indicated that factor scores from Factor 1 relate to all measures of correct performance on a trivia questionnaire, whereas factor scores from Factor 2 do not. When considering the size of the cor- relations between factor scores from Factor 1 and trivia recall, two thoughts should be kept in mind: (1) Memory for trivia is only one component of Factor 1, and (2) subjects were instructed to think of their own particular areas of interest when answering the two questions pertaining to trivia on The Memory Scale. A subject may consider himself excellent in trivia about Shakespeare, and consequently rate himself as excellent in trivia, and yet may not watch popular television shows. Since the trivia questionnaire clearly favored the television/cinema realm of trivia, anyone who spends little time watching television or attending the cinema would fare poorly on the trivia quiz. A more comprehensive trivia test, one that covers many more realms of trivia, may prove more sensitive to differences in trivia recall. In spite of the weaknesses of the present measure of trivia recall, the pattern of correlations suggests that a test of this nature taps an ability that is related to one cluster of self-perceptions of ability but not to the other. Perhaps scores from this test, along with scores from other tests of verbal ability, will form the ability analogue to the cluster of self-perceptions of memory ability that are represented by Factor 1 .

The correlation matrix reveals that the pattern of correlations for factor scores from Factor 3 parallels that of the number of incorrect answers, just as the pattern of correlations for factor scores from Factor 1 parallels that of the number of correct answers. A high factor score on Factor 3 suggests that the person perceives himself to be successful at remembering personal articles, dates, appointments, and the locations of objects. The explanation for the pattern of correlations for factor scores from Factor 3 may revolve around a possible strategy that is used to keep track of personal articles, dates, and the like. The strategy may entail the rapid retrieval of several possible answers (in everyday life, to a query such as, "Now where did I leave my keys?") with the understanding that the correct answer will be determined ultimately by reference to some external condition (here, the actual location of the keys). A person using this strategy would probably locate his keys quickly and report having a good memory for personal articles. A strategy of this

Table 2

Correlation Matrix

\begin{tabular}{|c|c|c|c|c|c|c|c|}
\hline Variables & 1 & 2 & 3 & 4 & 5 & 6 & 7 \\
\hline 1 Factor 1 & 1.000 & & & & & & \\
\hline 2 Factor 2 & .318 & 1.000 & & & & & \\
\hline 3 Factor 3 & .400 & .140 & 1.000 & & & & \\
\hline 4 Categories Attempted & .319 & -.033 & -.087 & 1.000 & & & \\
\hline 5.Categories & .348 & -.034 & -.172 & .875 & 1.000 & & \\
\hline 6 Categories Completed & .389 & .098 & -.011 & .481 & .593 & 1.000 & \\
\hline 7 Total Correct & .378 & .100 & .322 & .627 & .627 & .622 & 1.000 \\
\hline 8 Total Incorrect & .065 & .030 & .663 & -.045 & -.280 & -.095 & .420 \\
\hline 9 Total Attempted & .245 & .073 & .602 & .308 & .157 & .273 & .809 \\
\hline
\end{tabular}

Note-Correlation between Variables 8 and $9=.873$. Variables 1,2 , and 3 are factor scores from Factors 1, 2, and 3 . 
nature may be successful in situations in which one can continue to generate answers until the correct one is found, but it may prove disastrous in situations in which one must make a single, final answer without any external referent to aid in the selection of the "correct" answer. The strategy could produce many incorrect answers on a test such as the trivia questionnaire used in Experiment 2. The explanation certainly warrants further study. The correlations of factor scores from Factor 3 at least suggest that data reflecting errors on the part of the subject contain information relevant to the understanding of the three factors. These error data may be helpful in any attempt to find behavioral analogues to the three factors of self-perception of memory ability.

\section{EXPERIMENT 3}

The moderate correlations between factor scores from Factor 1 and successful performance on the trivia questionnaire show that a person's beliefs about his memory ability are related to actual memory ability. Experiment 3 explored the possibility that beliefs have a stronger relationship to behavior over which the subject has more control. For instance, a person's belief about his memory ability may be reflected in the amount of risk that he is willing to take in a task that involves memory. A person who believes that his memory for his research is excellent may risk disorganization and embarrassment by undertaking a colloquium presentation without the aid of notes. A person who believes that he has a poor memory for the way to a place that he has visited infrequently will carry a copy of the directions or will carry a map rather than risk getting lost. A person who believes that his memory for dates and appointments is excellent will not bother to write down dates or appointments in an appointment book even though he risks missing appointments. In this experiment, risk was defined operationally as the amount of play money that the subject was willing to wager in a two-contestant trivia contest. It was hoped that the two-contestant format would pressure each subject into making a more critical evaluation of his memory ability. The format would also give the wagering measure additional realism. It was predicted that while the subject's factor score from Factor 1 would have a moderate relationship to the subject's performance of the trivia questions in the quiz, the factor scores would be more strongly related to the amount of play money that the subject would wager on his performance.

Several other variables enter into the picture: The contestant's wager may depend, in part, on his general betting tendencies. The person may be a cautious and conservative better in general, or maybe the person is prone to reckless wagering. His wagers may depend on his interest in cinema/television trivia in general or on how well he fared in a recent discussion on the topic of cinema or television. There are also contextual confounds: Throughout the course of the contest, his pattern of betting and his total wagers may be influenced by his pattern of correct and incorrect answers. Perhaps getting the first two questions wrong will force the subject to adopt a more modest tactic than he otherwise would. Perhaps the subject is easily intimidated by an opponent's consistently successful performance, or perhaps the subject wagers more than is warranted in order to impress his opponent. The social influences were deemed too complex for detailed study in this research, and, indeed, they are far outside its focus. While attempts were made to account for some of these sources of variance, the aim was to keep the analysis simple and consistent with the focus of this research. It was decided to test each subject on several trivia questions in private some days before the trivia contest. In this way, measures of his wagering tendencies and his performance on a trivia task could be measured without the influences of an opponent. The following independent variables were obtained from the private trivia quiz.

(1) The amount of the wager placed on the first question-This first wager was an amount of play money that ranged from $\$ 0$ to $\$ 100$. It was considered a measure of the subject's betting tendencies or disposition before any performance variables influenced his betting.

(2) The total number of correct answers (on six questions)-The measure was considered a measure of the subject's ability to answer trivia questions. The validity of the measure may have been weakened by the small number of questions used in the quiz. A better measure would have been some form of trivia questionnaire, like the one used in Experiment 2; the small number of questions was chosen for practical reasons.

(3) The total amount wagered for the six questions-This measure was influenced by the subject's performance (that is, by the total number of correct answers) and by the amount of money that the subject tended to wager.

(4) The total winnings over the six questions-This measure was also influenced by the subject's performance and by the amounts that the subject tended to wager. The underlying construct of this variable and that of the variable of total amount wagered were considered ambiguous; their inclusion in the analysis was mainly for want of completeness rather than for any clear theoretical reason.

Since the subject's betting during the public twocontestant quiz was likely to be influenced by his progression of correct and incorrect answers and may have been influenced by the performance of his opponent, the dependent variable in this study was the amount of play money wagered on the first question of the trivia contest. This was the wager made before his performance or that of his opponent had a chance to influence the betting. 


\section{Method}

Subjects. Forty-seven subjects from basic psychology classes participated in this study. The study was conducted at the University of Connecticut at Stamford during the fall semester of 1979.

Materials. Two sets of six trivia questions were assembled. The questions were taken from a larger set of 50 trivia questions that, on the basis of norms collected in the spring of 1979 , were known to be answerable by a majority of students. The first set of six questions was administered in the private testing; the second set was administered in the format of a twocontestant trivia contest.

Procedure. Private session. Each subject was ushered into a quiz room that consisted of a table, two chairs, and paper and pencil for recording the subject's responses and wagers. The experimenter was an upperclass student. The subject was seated and given complete instructions. Subjects were told that prior to each question the experimenter would read the domain or category from which the trivia question was drawn. There were six categories used in this experiment: (1) television shows from the 1970s, (2) classic television shows from the 1960s, (3) films from the $1970 \mathrm{~s}$, (4) classic films from before 1970 , (5) recording stars and groups of the $1970 \mathrm{~s}$, and (6) recording stars and groups before 1970 . The questions required the names of characters and actors or actresses as answers.

The subject was "loaned" $\$ 100$ in play money. He was asked to wager an amount for each question, with the aim of maximizing his total winnings. The subject was told that the initial loan of $\$ 100$ would be subtracted from his total winnings at the end of the session. If the subject answered the question correctly, the amount wagered was added to his total winnings; if he answered incorrectly, the amount wagered was subtracted from his total winnings. Any questions of procedure were answered at this point in the session.

The experimenter then read the first question category and the subject placed the first wager. The question was then read aloud by the experimenter; the subject was given $1 \mathrm{~min}$ in which to respond. The subject's response was recorded and verified, and the appropriate adjustment was made to the subject's total winnings. This pattern was repeated for the remaining five questions in the private session. The same six questions in the same order were given to all subjects. The subjects were dismissed at the end of the session.

The two-contestant session. The public trivia quiz followed the private session by not less than 5 and not more than 10 days. Subjects were paired with opponents of the same sex but were not matched in any other fashion. Two subjects were ushered into a quiz room that consisted of a table, three chairs, and paper and pencils for the subjects' wagers. The subjects were seated facing each other at the ends of the table; the experimenter sat between them. The procedure was similar to that of the private session, with the following modifications. Both subjects were "loaned" $\$ 100$ in play money. Each subject wrote his bet on the paper in front of him after the experimenter read aloud the category from which the trivia question was to be drawn. The same six categories used in the private session were used here, although the questions were different. After the bets were placed, the experimenter read the question aloud. The first contestant to signal that he knew the answer was given an opportunity to answer aloud without any interruption from the opponent. If his answer was correct, his wager was added to his total winnings; if incorrect, his wager was subtracted from his total winnings and his opponent was given a chance to answer without penalty. If the first subject was correct in his answer, the opponent was considered the loser and had his wager subtracted from his total winnings, regardless of his ability to answer the question correctly. The subjects were dismissed at the end of the six questions.

\section{Results}

Factor scores from Factor 1 were calculated by the SPSS factor analysis subprogram as part of the solution reported in Experiment 1. Scores reflecting the four aspects of the subject's performance in the private trivia quiz and the amount of the first wager in the twocontestant quiz were tabulated.

The correlation matrix for these six variables is presented in Table 3. The dependent variable in the multiple-regression analysis was the amount of play money wagered on the first question of the twocontestant quiz. The first variable entered into the equation was the factor score from Factor 1. This variable accounted for a significant portion of the variance of the dependent variable $[\mathrm{F}(1,45)=5.338$, $p<.05]$. The $R^{2}$ at this step of the analysis equaled .106 , which is the square of the simple correlation between factor score and the dependent measure $(\mathrm{r}=.325)$. One way of illustrating this relationship is by classifying subjects into the three categories "high" (above 1 standard deviation), "middle" (between +1 and -1 standard deviation), and "low" (below 1 standard deviation), according to the subject's factor score on Factor 1. The mean for this particular distribution of factor scores was $.0071(\mathrm{SD}=.8464)$. The 7 subjects classified as high placed an average wager of $\$ 45.71$ $(S D=21.49)$, the 34 subjects classified as middle placed an average wager of $\$ 35.12(\mathrm{SD}=21.88)$, and the 6 subjects classified as low placed an average wager of $\$ 30.00$ $(\mathrm{SD}=15.81)$.

The type of multiple-regression analysis used here was a hierarchical analysis in which the significance of the increase in $\mathrm{R}^{2}$ was assessed at each addition of a new variable. The second variable entered into the equation was the amount of the first wager in the private session. This was conceived of as a measure of the subject's betting tendencies. The simple correlation between

Table 3

Correlation Matrix

\begin{tabular}{|c|c|c|c|c|c|c|}
\hline Variables & 1 & 2 & 3 & 4 & 5 & 6 \\
\hline 1 First Wager/Two Contest & 1.000 & & & & & \\
\hline 2 Factor 1 & .326 & 1.000 & & & & \\
\hline 3 First Wager/Private & .631 & .112 & 1.000 & & & \\
\hline 4 Total Correct & .351 & .161 & .176 & 1.000 & & \\
\hline 5 Total Wager & .514 & .146 & .229 & .495 & 1.000 & \\
\hline 6 Total Winnings & .256 & .106 & .119 & .773 & .616 & 1.000 \\
\hline
\end{tabular}

Note-The first wager in the two contestant quiz was the dependent variable in the multiple regression. 
this first wager and the first wager in the two-contestant quiz was .631. In the multiple-regression analysis, the addition of this variable into the equation increased the $\mathrm{R}^{2}$ to .463 . The increase was significant $[F(1,44)=$ $29.326, p<.001]$. Clearly, it is important to have some knowledge of the subject's betting tendencies when attempting to predict his betting behavior in another context.

The third variable in the equation was the total number of questions that the subject answered correctly in the private quiz. It was conceived of as an approximate measure of the subject's trivia ability. The $\mathrm{R}^{2}$ increased to .507; however, this increase was not significant $[F(1,43)=3.803$, n.s. $]$. The trend was clear: Subjects who did well on the private trivia questions tended to wager more on the first question in the two-contestant quiz. The 12 subjects who answered five or six (of six) questions correctly wagered a mean amount of $\$ 42.83$; the 23 subjects who answered three or four questions correctly wagered an average amount of $\$ 37.83$; and the remaining 12 , who answered one or two questions correctly, wagered an average amount of $\$ 25.83$. The prior entry of the first two variables in the equation makes this trend meaningful and nonredundant only in isolation: If this variable were entered into the equation first, the $F$ would be 6.308 , which, with 1 and 45 degrees of freedom, would be significant at the .05 level.

The fourth variable, the total amount of winnings in the private quiz, did not increase the $R^{2}$ by any measurable amount. The $R^{2}$ remained at .507 . The final variable, the total amount wagered in the private session increased the $R^{2}$ to .610 . This increase was significant $[F(1,41)=10.828, p<.01]$. The multiple $R$ with all of the variables in the equation was .781 .

It could be argued that a more conservative test of the significance of the factor score from Factor 1 as a predictor of the subject's first wager in the twocontestant quiz would be to enter the factor score variable into the regression equation after all of the private session variables are in the equation. If the increase in $R^{2}$ is still significant, then it can be argued that the variance accounted for by the factor score is meaningful and unique. The $R^{2}$ with all of the private session variables in the equation was .571; the addition of the factor score from Factor 1 still increased the $\mathbf{R}^{2}$ by a significant amount $[F(1,41)=4.101, p<.05]$. The $\mathrm{R}^{2}$ increased to .610 .

It was suggested in Experiment 1 that males and females differed with respect to Factor 1: Are these differences reflected in the trivia contest? Males from this sample posted a higher mean factor score for Factor 1 $(.1783 ; \mathrm{SD}=.8693)$ than the females did $(-.1196$; $\mathrm{SD}=.8222$ ). Males also answered more questions correctly than the females did (4.1 questions vs. 3.3 questions). An interesting observation was that while males placed a lower wager, on the average, in the first question of the private quiz ( $\$ 14.25$ vs. $\$ 19.15)$, they placed a higher bet on the first question in the two- contestant quiz (\$37.50 vs. $\$ 34.96$ ). Unfortunately, none of these sex differences was significant.

\section{Discussion}

A person's beliefs about his ability to answer trivia questions, represented, in general, by factor scores from Factor 1, seemed to influence the amount of play money he was willing to wager on the first question of the two-contestant trivia quiz. The relationship was not stronger than those observed between factor scores from Factor 1 and the measures of trivia recall in Experiment 2 , which suggests that the wagering measure is not necessarily more sensitive to the influence of a person's beliefs about his memory ability than some measure of ability would be. Still, the results suggest that a wagering measure or some other measure of risk can prove useful as an adjunct to measures of ability; like measures should be included in any large-scale endeavor to validate the factors reported in Experiment 1.

The performance variables that were measured in the private quiz session held prior to the two-contestant quiz were observed to be important predictors of the amount of the first wager. A subject will have a style of betting that influences the relative amount he is willing to wager. And he will also remember aspects of how well he performed in the previous session: In this experiment, the total amount of money wagered appeared to be the relevant variable. It should come as no great surprise that subjects use prior performance as relevant information in making a wager on their future performance: High school students do so when they choose a college and wager the tuition.

Two aspects of the results of Experiment 3 are confusing. First, it is very good to show that scores from Factor 1 are related to the amount wagered on the first question in the two-contestant quiz, but what account can be given for the low correlation observed between factor score and the first wager made in private? One possibility is that subjects were not adjusted to the wagering on this very first wager. A relevant observation here is that males, who had a higher mean factor score on Factor 1, tended to make a more conservative wager than the females on the first question in the private quiz. It is possible that the males, on the basis of their subsequent performance, which was somewhat better, on the average, than that of the females, adjusted their wagers to a level more in line with their perceptions of their abilities. This adjustment may be reflected in the higher correlation between factor score and first wager in the two-contestant quiz. Another possibility is that the wagering measure only "works" in a competitive setting. This possibility could be explored by reversing the order of the testing: Such a procedure would be necessary to rule out naive or cautious betting as an explanation for the low correlation between factor score and the first bet made in private. The effect of the social setting may be quite subtle: Perhaps the wager with play money was taken more seriously in the public 
setting than it was in the private quiz because the play money gains value through the possibility of social rewards (such as recognition as the winner). One way of sidestepping the problem of the value of play would be to use real money in the contest. If the wagering measure depends on a social context for its usefulness as a measure of the influence of a person's beliefs about his memory ability, its use in studies that attempt to validate the three factors will be limited: While the domain of trivia lends itself to a contest format, many of the other domains represented in the factors do not. Although these accounts seem plausible and suggest further investigation, the low correlation between factor score and first wager made in private remains a serious problem with this study.

A second confusing aspect of the results is that the correlation between factor score and performance on the six questions in the private session was nonsignificant. The discussion of the results from Experiment 2 dealt with the problem of relating factor scores to performance scores to some extent by pointing out that memory for trivia is only one domain in Factor 1 and that subjects gave their own definitions to the category of trivia. Here it can be added that since the number of questions used to measure performance was small, the "weight" of chance was increased. The small number of questions may have seriously weakened the validity of this task as a measure of the subject's ability to recall trivia. Even so, performance on these few questions seemed to influence the subject's wagering in the second set of questions, especially since the subject was told that the questions in the second set would be similar to those in the first.

Experiment 3 was designed to create a context in which the subject could place a wager prior to his performance on a memory task. Although this wagering measure has proved worthwhile, it seems that the practical concessions made in the experimental setting have created problems that weaken the overall impact of the results. Still, the form of the study offers an example of the direction that research can take in the investigation of the pragmatics of a person's self-theory of memory. Refinements in design may yield more satisfactory results.

\section{GENERAL DISCUSSION AND CONCLUSION}

The advantage of conceptualizing the self-report of memory as self-theory of memory lies mainly in the availability of a vast array of hypotheses, methods, and data concerning self-theory that have accumulated in other areas of cognitive and social psychology. The existence of a self-theory will never be established experimentally, but the paths of research from a self-theory framework lead to many potentially rewarding areas of inquiry.

One such path involves a more detailed investigation into the structure of a self-theory of memory. The three factors that emerged from the factor analysis of The Memory Scale do not reflect three different selftheories of memory ability but, rather, reflect three general areas within a person's self-theory. The factor scores indicate that there are some subjects who are located to the extreme positive end of one factor and to the extreme negative end of the other two. Here, perhaps, it may be fruitful to look for a different selftheory: a theory that differs radically from the others in terms of hierarchical organization, complexity, dimensionality, and so on (cf. Scott, Osgood, \& Peterson, 1979).

A second path involves the inquiry into the existence of behavioral or ability analogues to the three factors of self-perception. This would involve assembling a battery of memory tests, each testing one of the memory domains included in The Memory Scale. Experiment 2 was one step in this direction: The results indicated that a subject's performance on a paper-and-pencil trivia questionnaire was correlated with his factor score from Factor 1. Factor 1 was described as a verbal memory factor. It remains difficult to construct memory tasks that will tap the domains of memory clustered in Factor 2 . The development of such tasks will be essential to the complete validation of the three factors reported in Experiment 1.

A third path of inquiry takes us into those behaviors that, while not memory abilities per se, may be influenced by a person's beliefs about his memory ability. Experiment 3 was one step in this direction: Results indicated that the amount of play money that a subject wagered in a two-contestant trivia quiz was related to his factor score from Factor 1. Although methodological problems weakened their overall impact, the results suggested that behaviors related to memory beliefs can provide useful information and should be included, if feasible, in any attempt to validate the three factors. The amount of time that a person spends talking about his past in a group discussion and the speed with which a person volunteers to speak in a memory-related discussion would be other measures of this type.

A fourth path of inquiry enters into the realm of cognitive style or cognitive correlates of the three factors. A cognitive style refers to a way in which an individual conceives of and organizes his environment (Goldstein \& Blackman, 1978): Field independence, tolerance for ambiguity, cognitive complexity, and so on, are examples of cognitive styles. Are there different cognitive styles associated with the extremes of these three factors? One could also inquire into other cognitive realms: Are there different interests or perceptual skills, formerly thought to be unrelated to memory ability, that are related to a person's beliefs about his memory ability? Are there differences in retrieval strategy, encoding strategy, or organization of memory that are related to one or another factor? Finally, are the memory experiences themselves different in nature for a person who is, say, extreme on Factor 2? Are 
they more visual, or more emotional? Questions such as these form the basis of a recent study (Sehulster, Note 4).

A fifth, but by no means final, path of inquiry enters into the crucial realm of trust and certainty in memory. The memory experiences of trust and certainty in memory clustered with Factor 1 in the first experiment, and it was suggested that perhaps subjects used the verbal memory abilities as the basis for an assessment of trust in memory. The implications of a lack of trust or a lack of faith in one's memory require attention. It has been suggested that memory lies at the base of one's sense of self: The implications of a lack of trust in one's memory may indeed be profound (Sehulster, Note 1).

\section{REFERENCE NOTES}

1. Sehulster, J. Memory, trust, and reality. Paper presented at a conference for Psychologists of Upstate New York, Hamilton, New York, October 1979.

2. Herrmann, D. Know thy memory: The use of questionnaires to assess and study memory. Unpublished manuscript, 1980.

3. Herrmann, D. How people answer memory questionnaires: $A$ theory of memory introspection. Paper presented at a conference for Psychologists of Upstate New York, Hamilton, New York, October 1979.

4. Sehulster, J. Phenomenological correlates of a self-theory of memory. Manuscript submitted for publication, 1980.

\section{REFERENCES}

Aronson, E. The theory of cognitive dissonance: A current perspective. In L. Berkowitz (Ed.), Cognitive theories in social psychology. New York: Academic Press, 1978.

Bateson, G. Steps to an ecology of mind. New York: Ballentine Books, 1972.

BECK, A. Cognitive therapy and the emotional disorders. New York: International Universities Press, 1976.

Вем, D. Self perception theory. In L. Berkowitz (Ed.), Cognitive theories in social psychology. New York: Academic Press, 1978.

Festinger, L. A theory of social comparison processes. Human Relations, 1954, 7, 117-140.

Flavell, J., \& Wellman, H. Metamemory. In R. Kail \& J. Hagen (Eds.), Perspectives on the development of memory and cognition. Hillsdale, N.J: Erlbaum, 1977.

Goldste in, K., \& Blackman, S. Cognitive style: Five approaches and relevant research. New York:Wiley, 1978.

HALEY, J. Uncommon therapy: The psychiatric techniques of Milton H. Erickson, M.D. New York: Norton, 1973.

Herrmann, D., \& Neisser, U. An inventory of everyday memory experiences. In M. Gruneberg, P. Morris, \& R. Sykes (Eds.), Practical aspects of memory. London: Academic Press, 1979.

JAMEs, W. The principles of psychology (Vol. 1). New York: Dover Publications, 1950.

KELLY, G. The psychology of personal constructs. New York: Norton, 1955.

KLEINKE, C. Self-perception: The psychology of personal awareness. San Francisco: Freeman, 1978.
Linton, M. Real-world memory after six years: An in vivo study of very long term memory. In M. Gruneberg, P. Morris, \& R. Sykes (Eds.), Practical aspects of memory. London: Academic Press, 1979.

Malcom, N. Memory and mind. Ithaca, N.Y: Cornell University Press, 1977.

Mead, G. Mind, self, and society. Chicago: Chicago University Press, 1934.

Nie, N., Hull, C., Jenkins, J., Steinbrenner, K., \& Bent, D. Statistical package for the social sciences (2nd ed.). New York: McGraw-Hill, 1975.

Nunnally, J. Psychometric theory (2nd ed.). New York: McGrawHill, 1978.

Russeld, B. The analysis of mind. New York: Humanities Press, 1921.

Scott, W., Osgood, D., \& Peterson, C. Cognitive structure: Theory and measurement of individual differences. Washington, D.C: Winston, 1979.

Shave R, K. An introduction to attribution processes. Cambridge, Mass: Winthrop, 1975.

Tulving, E. Episodic and semantic memory. In E. Tulving \& W. Donaldson (Eds.), Organization of memory. New York: Academic Press, 1972.

Underwood, B., Boruch, R., \& Malmi, R. Composition of episodic memory. Journal of Experimental Psychology: General, 1978, 197, 393-419.

Watzlawick, P., Weakland, J., \& Fisch, R. Change: Principles of problem formation and problem resolution. New York: Norton, 1974.

Wegner, D., \& Vallacher, R. Implicit psychology: An introduction to social cognition. New York: Oxford University Press, 1977.

\section{NOTES}

1. Some clinicians (cf. Beck, 1976; Haley, 1973; Kelly, 1955; Watzlawick, Weakland, \& Fisch, 1974) have suggested that a client's self-theory is the source of the client's problems; their therapies often involve getting the client to behave in such a way as to precipitate a change in his self-theory.

2. The results of an earlier analysis were reported by the author at Colgate University (Sehulster, Note 1) in October 1979. At that time, there were 666 subjects in the study; 24 memory domains were used in the factor analysis. The revisions of the memory domains for the present study entailed decomposing those domains that had extremely low correlations among the statements within the domain. For example, the three memory experiences involving locating objects (in the present analysis) were grouped into a single domain in the 1979 analysis. The revisions of the memory domains changed the loadings of the trust, certainty, and social comparison experiences from ambiguous to clearly loading on Factor 1.

Factors beyond the initial three factors were characterized by few defining variables and very weak loadings.

3. An orthogonal (varimax) rotation was tried as an aside with the three initial factors: The results were essentially identical to those reported here.

(Accepted for publication August 4, 1980; revision accepted October 31,1980 .) 